\title{
A SOCIOLOGIA PÚBLICA EM TEMPOS DE BARACK OBAMA ${ }^{1}$
}

\author{
Michael Burawoy*
}

\begin{abstract}
O presente artigo, baseado em discurso dirigido à Sociedade Japonesa de Sociologia, na Universidade de Tohoku, recoloca as formulações centrais da sociologia pública, identificando os quatro estilos do fazer sociológico. Isso é feito à luz do cenário aberto com a profunda crise por que passa o sistema capitalista mundial. Mesmo ciente das diferentes tradições nacionais e da desigualdade internacional, e apesar delas, acreditamos que, como sociólogos, compartilhamos uma ambição e uma missão comum, que seria o combate ao paradigma baseado no fundamentalismo do mercado, que atualmente demonstra gravíssimos sinais de crise e de exaustão. Nesse sentido, resulta como tarefa primordial que os sociólogos canalizem as reações à crise em direção à criação de uma sociedade civil mais fortalecida e democrática, e de uma esfera pública mais robusta e inclusiva.

PALAVRAS-CHAVE: sociologia pública, sociedade civil, esfera pública, fundamentalismo de mercado.
\end{abstract}

Esta é minha primeira visita ao Japão. Portanto, é com grande inquietação e expectativa que me dirijo a vocês sobre o tema da sociologia públi$c a$. Como etnógrafo atento às especificidades das condições culturais, estou plenamente ciente dos perigos de levar a vocês uma ideia formulada a partir de um contexto nacional tão diferente. A transmissão de um conceito na sociologia já é tarefa difícil, sujeita às variações das tradições regionais. Quando, além disso, somam-se os múltiplos sentidos da palavra "público", enfrentamos aí problemas aparentemente insolúveis.

A partir do livro de Hasegawa (2004) a respeito da sociedade civil, entendi o quão ambíguo é o termo "público" em japonês, que contém conotações "oficialescas e burocráticas" inexistentes no mundo de língua inglesa. Cada país atribui a

* Doutor em Sociologia pela Universidade de Chicago. Professor do Departamento de Sociologia da Universidade da Califórnia em Berkeley.

Department of Sociology, University of California, Berkeley, CA 94720. burawoy@berkeley.edu

${ }^{1}$ Este artigo foi baseado em um discurso dirigido à Sociedade Japonesa de Sociologia, na Universidade de Tohoku, em Sendai, no dia 23 de Novembro de 2008. (N. do A.) Traduzido por Fernando Rogério Jardim, mestrando do Departamento de Sociologia da FFLCH-USP. Revisão dos organizadores do dossiê. esse termo seus próprios sentidos de tradução. Por exemplo: na Rússia, o termo "público" é tão depreciativo e difamatório, devido em parte à sua associação com o regime soviético, que os tradutores da sociologia "pública” têm tentado encontrar palavras alternativas, sem muito êxito.

A sociologia "pública" vê-se realmente prejudicada com as traduções! A tarefa de interpretála torna-se ainda mais árida devido aos intensos debates - tanto nos Estados Unidos como no exterior - acerca do sentido, do âmbito, das armadilhas e das patologias da sociologia pública. Por fim, a circulação de uma ideia é especialmente problemática quando seu contexto originário é uma superpotência mundial hegemônica; e, ainda mais, quando tal ideia vem acompanhada de reivindicações de universalismo. Seu caráter suspeitoso é, nesses casos, assegurado!

Mesmo assim, quando eu aceitei dialogar com vocês sobre a sociologia pública, é porque acredito que nós, como sociólogos, a despeito das tradições nacionais e malgrado nossas desigualdades internacionais, compartilhamos uma ambição e uma missão comum: a de combater o fundamentalismo 
do mercado que se espalhou pelo planeta - um paradigma que atualmente vem demonstrando gravíssimos sinais de crise e de exaustão.

Com efeito, podemos dizer que o Japão esteve à frente desse jogo: sua crise econômica dos anos 1990 foi a precursora da crise financeira que hoje envolve os Estados Unidos e, com ele, o resto do mundo. Os três cavaleiros do apocalipse econômico - a desregulação financeira, a privatização da natureza e dos serviços sociais, bem como a repressão que afeta o trabalho - vieram para ficar, trazendo a recessão mundial. Porém, assim como a Grande Depressão dos anos 1930 deu origem tanto ao fascismo e ao stalinismo como ao New Deal eà socialdemocracia, essa depressão apresentará antecipadamente seus próprios desafios, possibilidades e oportunidades. No contexto atual, estamos nos aproximando de uma encruzilhada, pela qual os sociólogos podem e devem se juntar àqueles que Weber chamou dos homens e mulheres agentes da história.

A eleição de Barack Obama como o primeiro afroamericano presidente dos Estados Unidos - um evento histórico por si mesmo - coincidiu com o agravamento da crise financeira. Isso assinalou o provável início de uma reviravolta americana contra o fundamentalismo do mercado - um contra-ataque que se impôs ao novo governo tal como se impusera ao desfecho do governo anterior. O que ainda não está claro é a coloração ideológica que tal contra-ataque poderá assumir, sua conexão com os movimentos sociais subalternos e se suas respostas permanecerão confinadas ao âmbito nacional ou se elas deverão ser também globais. Conseguirá o movimento da campanha de Barack Obama deslanchar, continuar e, nesse caso, será ele poderoso o bastante para forçá-lo numa direção progressista à la New Deal, diante da crise vindoura? Poderá sua origem racial e retórica inflamada acender as lutas por justiça social nos Estados Unidos e mesmo no exterior? Terminará Barack Obama prisioneiro da esperança e da imaginação que ele próprio inspirou? Há uma real incerteza sobre o que o futuro nos reserva.

Sejam quais forem as direções que o governo Obama tomar para conter a crise - e as direções serão inegavelmente contraditórias - os sociólogos têm seus próprios interesses em canalizar as reações em direção à criação de uma sociedade civil mais fortalecida e democrática, e de uma esfera pública mais robusta e inclusiva. Ora, não apenas porque é a atitude mais progressista a se tomar, mas também porque a vitalidade da sociologia está enraizada na sociedade civil. Assim, nestes tempos de indefinição e de insegurança, a sociologia pública, isto é, a sociologia do engajamento com os diversos públicos, terá tanto a oportunidade como a obrigação de defender os fundamentos que sustentam a sociologia e, por consequência, o interesse comum e universal.

Por essas razões, meu pronunciamento hoje terá cinco partes. Eu começarei descrevendo a gênese do conceito de sociologia pública, para ajudálos a compreender exatamente seu significado e importância. Em seguida, partirei de uma visão particular em direção à minha formulação geral sobre os quatro tipos de conhecimento sociológico que formam a divisão do trabalho na sociologia e, para ser exato, em qualquer outra disciplina - sendo todos esses tipos indispensáveis ao florescimento disciplinar. A partir do geral, eu retornarei ao particular, apontando para diferentes articulações nacionais dessa divisão do trabalho sociológico, bem como para os conflitos que elas engendram. Apesar dos antagonismos, os sociólogos compartilham de um programa distintivo, enraizado na defesa e na expansão da sociedade civil - o que me leva ao ponto final do texto. Com suas raízes fincadas na sociedade civil, os sociólogos têm particular interesse em responder e combater o fundamentalismo do mercado e a crise financeira provocada por ele. Inspirados por este momento histórico, os sociólogos públicos poderão emergir de seus "nichos e casulos acadêmicos", para assumir seus lugares e influir na direção da sociedade.

\section{A VISÃO DA "SOCIOLOGIA PÚBLICA"}

Minha concepção de sociologia pública surgiu na África do Sul. Eu retornei lá em 1990, após 
a suspensão do boicote acadêmico ao Apartheid. Era minha primeira visita desde 1968, sendo então convidado para discursar na Associação dos Sociólogos Sul-Africanos - ASSA. Por dez anos, eu realizei pesquisas empíricas em indústrias na Hungria socialista. E lá estava eu na África do Sul para falar sobre a derrocada do socialismo real, tal como fôra experienciada por sua classe trabalhadora. Havia, então, muito interesse sobre o tema, pois a luta pela libertação sul-africana centrada nos trabalhadores e influenciada por suas conexões com a União Soviética - havia absorvido especialmente a ideologia socialista. Mas não somente por isso: 1990 marcou o início do fim do regime de segregação e o clímax das lutas operárias e campesinas que derrubaram o último regime colonial da África. Se as lutas de classe foram explosivas, levando abaixo o regime soviético, o que aconteceria com seus protagonistas na nova África do Sul?

Assistindo aos painéis na conferência da ASSA, em 1990, fiquei muito estimulado e impressionado com a imersão dos sociólogos sul-africanos nas trincheiras da sociedade civil, com os debates inflamados que surgiam daquelas batalhas e com a originalidade das suas teorias sobre a raça, $o$ Estado e os movimentos sociais. Quão diferente tudo aquilo era do que eu estava habituado a ver nos Estados Unidos! Uma sociologia superprofissional, que fetichizava sua separação da sociedade; uma comunidade autocentrada, que organizava e policiava os intercâmbios de ideias e de artigos, ambos distantes do universo que eles estudavam; uma organização que recrutava seus graduados como se eles estivessem ingressando numa sociedade secreta! Ali estava, então, a diferença entre a sociologia profissional e a sociologia pública.

Durante os anos 1990, eu deixei a Hungria e sua transição para o mercado para dedicar-me a pesquisar a Rússia, quando eu acompanhei o melancólico declínio, ou a involução, como eu chamei, do sistema soviético - que produziu gigantescas disparidades de renda e das condições de existência. Mas, antes do início desse declínio, houve alguns momentos de esperança. Durante o crepús- culo da Perestroik $a^{2}$ e nos anos de abertura política da Rússia pós-soviética, eu testemunhei a vitalidade de uma sociologia pública que parecia surgir do nada e vinha na onda de uma sociedade civil efervescente. Os últimos suspiros da era soviética deram início aos anos dourados da sociologia. No entanto a subsequente e calamitosa transição soviética para a economia de mercado transformou os sociólogos em meros aplicadores de pesquisas de opinião pública a serviço do mercado, segundo a forma mais tosca de ciência aplicada e orientada pelas demandas da clientela.

Com poucas exceções notáveis, é claro, a sociologia soviética nunca teve autonomia profissional; ela sempre foi uma ferramenta ideológica do partido estatal e, por isso, sua recaída numa função instrumental não era nenhuma surpresa. Se a sociologia sul-africana mostrava o lado obscuro da sociologia profissional estadunidense, a sociologia russa mostrava o lado positivo dela, porque, sem um forte apoio da sociologia profissional, não existiria nenhuma sociologia digna desse nome. Tampouco existiriam a sociologia pública e a sociologia para políticas públicas. Não é à toa que os sociólogos russos afirmam hoje que a sociologia pública, na Rússia, deverá ser, antes de mais nada, a defesa pública de uma sociologia profissional realmente autônoma.

Sim: nós precisamos da sociologia profissional, mas nós também devemos mantê-la sob controle. Ela precisa estar sujeita à contínua crítica: a comunidade dos sociólogos profissionais não pode ser responsabilizada individualmente pela produção da autocrítica. Precisamos desenvolver, então, um agrupamento de sociólogos críticos cuja tarefa será questionar os fundamentos da sociologia profissional e seus programas de pesquisa. Nos Estados Unidos, pensamos em figuras como Robert Lynd (1939), Pitirim Sorokin (1956), Alvin Gouldner (1970), Wright Mills (1959) e Dorothy Smith (1987) como casos exemplares de sociólogos críticos. Ao desenterrar os fundamentos axiológicos da sociolo-

${ }^{2}$ Conjunto de reformas econômicas e políticas iniciado por Mikhail Gorbachov na União Soviética em 1985. (N. do T). 
gia profissional e mantê-los sob exame, debate e discussão, a sociologia crítica não apenas redireciona a sociologia profissional como também apoia e revivifica a sociologia pública.

\section{DIVIDINDO O TRABALHO SOCIOLÓGICO}

Nós temos, então, quatro tipos de conhecimento sociológico: o profissional, o crítico, o público e o orientado para políticas públicas. Eu desdobrei esse esquema a partir das minhas próprias experiências em vários países; porém, sua ubiquidade acompanha duas questões centrais que, como sociólogos profissionais, todos nós insistimos de forma muito conveniente. A primeira questão é: conhecimento para quem? Estaríamos dialogando e nos dirigindo a nós mesmos ou a audiências exteriores à academia? A segunda questão é: conhecimento para quê? Aqui eu evoco uma distinção que podemos encontrar no núcleo da obras de Weber, dos pensadores da Escola de Frankfurt e da teoria crítica: a distinção entre um conhecimento instrumental, preocupado em determinar os meios apropriados a determinados fins, e um conhecimento reflexivo, dedicado à discussão daqueles mesmos fins.

Sendo assim, a sociologia para políticas públicas define-se como sendo a resolução de "problemas" propostos por seus clientes. Esses clientes podem ser o Estado, ONGs, um político, um sindicato ou, geralmente, qualquer instituição que tenha metas previamente definidas e recursos suficientes para obter os serviços de um sociólogo submisso.

A sociologia profissional, por sua vez, procura resolver "quebra-cabeças" definidos pelos programas de pesquisa. Quebra-cabeças são apenas aqueles que se encaixam num quadro teórico. Desse modo, o desenvolvimento econômico japonês foi apenas um quebra-cabeça no contexto da teoria evolucionária da modernização. A mudança social constituiu-se apenas um quebra-cabeça dentro do quadro conceitual do estrutural-funcionalismo, o qual tomava como dados a estabilidade social e o consenso moral. A rebelião estudantil foi um quebra-cabeça dentro da sociologia política somente porque qualquer coisa além dos partidos políticos e do sistema eleitoral, como os movimentos sociais, seria visto como algo irracional e inexplicável. Os gargalos de produção foram um quebra-cabeça para a sociologia industrial somente porque ela assumira de antemão que os operários e os gerentes tinham um interesse comum. As variações nacionais na mobilidade social continuaram sendo um quebracabeça dentro da teoria da estratificação, porquanto a estrutura de ocupações era considerada irrelevante. Eis aí como a ciência avança: tomando por referência uma série de pressupostos que determinam um paradigma, combatendo suas contradições internas e anomalias externas.

Um pesquisador bem sucedido não poderá questionar aqueles pressupostos - sua heurística negativa, como Imre Lakatos (1978) a chamou mais do que um jogador de xadrez poderá questionar as regras do jogo que joga. Essa é uma das razões pelas quais a sociologia crítica é tão importante: os sociólogos, imersos em seus programas de pesquisa, não podem resolver seus quebra-cabeças e, ao mesmo tempo, questionar os pressupostos sobre os quais os quebra-cabeças estão fundados. Para isso, eles precisam de pessoas especializadas em questionar tais pressupostos, quer dizer, os sociólogos críticos. Aqui vemos a crítica de Sorokin (1956) à obsessão quantitativa dos sociólogos americanos, ou as críticas de Gouldner (1970) ao predomínio do estrutural-funcionalismo.

Se a sociologia crítica envolve um diálogo entre os sociólogos a respeito dos fundamentos da sociologia profissional, a sociologia pública envolve um diálogo com os públicos para além da academia e a respeito dos fundamentos da sociedade.

Quadro 1 - A divisão do trabalho sociológico

\begin{tabular}{|l|c|c|}
\hline & $\begin{array}{c}\text { Audiência } \\
\text { acadêmica }\end{array}$ & $\begin{array}{c}\text { Audiência extra- } \\
\text { acadêmica }\end{array}$ \\
\hline $\begin{array}{l}\text { Conhecimento } \\
\text { instrumental }\end{array}$ & $\begin{array}{c}\text { Sociologia } \\
\text { profissional }\end{array}$ & $\begin{array}{c}\text { Sociologia para } \\
\text { políticas públicas }\end{array}$ \\
\hline $\begin{array}{l}\text { Conhecimento } \\
\text { reflexivo }\end{array}$ & Sociologia crítica & Sociologia pública \\
\hline
\end{tabular}


Para que se possa avaliar melhor minha concepção da sociologia pública, deixem-me fazer uma distinção entre a sociologia pública tradicional e a sociologia pública orgânica. A sociologia pública tradicional inclui quase todas as celebridades da nossa disciplina. Um exemplo que eu posso tirar do meu próprio departamento em Berkeley inclui Robert Bellah - o meio intérprete do Japão e também o autor-líder de um livro amplamente lido: Habits of the heart (Bellah etal, 1985), um relato acerca do individualismonorteamericanonumalinhagem que remonta a Tocqueville ${ }^{3}$ e David Riesman, ${ }^{4}$ ambos sociólogos públicos tradicionais por direito próprio. Então, teríamos de incluir também Robert Blauner (1972), cuja radical exposição do racismo estadunidense Racial oppression in America - foi bastante lida nos anos 1970. Mais recentemente, os livros The second shift (...) e Time bind (...) de Arlie Hochschild (1989; 1997) foram textos-chave nos debates sobre trabalho e família. Todos esses livros trazem uma perspectiva sociológica às questões públicas, ou, segundo as imortais palavras de Wright Mills (1959), eles transformam problemas privados em questões públicas. $\mathrm{E}$ eles fazem isso por meio de um exercício especificamente sociológico de mostrar a conexão entre a microexperiência individual ea macroestrutura social.

Os públicos aos quais a sociologia pública tradicional se dirige são amplos, passivos, rarefeitos e dominantes. Esses públicos têm uma presença amorfa. Com efeito, para Mills, eles dificilmente poderiam subsistir em uma sociedade de massas, assim como para Bourdieu (2000) - outro exemplo de sociólogo público tradicional - as pessoas comuns eram impermeáveis à mensagem sociológica. Habituadas à submissão, elas não podiam entender as condições da sua própria existência submissa. Então, para quem Bourdieu escrevia? Anthony Giddens (1984) - outro exemplo de sociólogo público tradicional - assume a posição inversa e afirma que as pessoas comuns absorvem rapidamente a mensagem sociológica, tanto que aqui-

${ }^{3}$ Tocqueville, Alexis. A democracia na América. Belo Horizonte: Itatiaia, 1977. (N. do T.).

${ }^{4}$ Riesman, David. A multidão solitária. São Paulo: Perspectiva, 1995. (N. do T.). lo que é pensamento sociológico hoje será sabedoria popular amanhã! Todos esses comentadores compartilham a perspectiva de que a educação sociológica viria de cima para baixo.

Bem diferente é a sociologia pública orgânica, que pressupõe, nas comunidades subjugadas, a existência, para usar a linguagem de Antonio Gramsci (1971), de um cerne de bom senso contido dentro do senso comum das pessoas. A educação sociológica é um diálogo sem mediação entre um sociólogo e um público (presencial ou presumido), que mobiliza a sociologia na elaboração dum entendimento que todos nós temos da estrutura social. Com exclusão de Gramsci, nós encontramos aqui renomados educadores como Paulo Freire (1970) e feministas como Dorothy Smith (2005), que acreditavam no trabalho realizado a partir das experiências dos oprimidos. Aqui nós poderíamos igualmente incluir Touraine (1988) e sua sociologia da ação, que aprofunda a percepção dos movimentos sociais militantes por meio das discussões e intervenções orquestradas pelos sociólogos. Nesses casos, os públicos são mais densos que rarefeitos, mais locais que amplos, mais ativos que passivos, mais antagonistas que dominantes.

Essa sociologia pública orgânica, que trabalha nas trincheiras da sociedade civil, é invisível bem diferente da sociologia pública tradicional, cuja eficácia depende justamente da sua visibilidade. O grande desafio para os sociólogos públicos orgânicos é negociar três conjuntos de relações de poder: o primeiro, dentro da comunidade acadêmica, que, com frequência, condena e rejeita tais engajamentos; o segundo, entre o próprio sociólogo e a comunidade com a qual ele se compromete; e o terceiro, as relações de poder dentro daquela comunidade estudada. Por sua vez, o grande desafio dos sociólogos públicos tradicionais é primeiramente lidar com os mediadores e intermediários das suas mensagens à sociedade. Não é surpresa nenhuma que Bourdieu (1998) e Mills (1956) tenham ambos atacado os meios de comunicação de massa, dos quais eles dependiam para divulgar ao público suas opiniões críticas.

Com frequência, verifica-se uma profunda 
animosidade entre os dois tipos de sociólogos públicos: o sociólogo público tradicional despreza os encontros íntimos com os públicos e os considera “contaminantes”, ao passo que os sociólogos públicos orgânicos desprezam o conhecimento encubado na academia, considerando-o um serviçal do poder. A mútua hostilidade tem seu fundamento na hierarquia acadêmica, assim como possui raízes ideológicas ocultas. Mas eu argumentarei que cada uma delas poderá se beneficiar da presença da outra: a sociologia pública tradicional conferirá legitimidade adicional à sociologia pública orgânica, recebendo dela a vitalidade e a imaginação provenientes dos seus intensos engajamentos públicos.

\section{AS CONFIGURAÇÕES NACIONAL E GLOBAL DO CAMPO SOCIOLÓGICO}

Até aqui, nós nos dirigimos do particular para o geral: fomos das experiências específicas da sociologia em diferentes países e chegamos às questões básicas que definem a matriz do conhecimento disciplinar. Retornemos, agora, ao particular. Nosso esquema, em quatro partes (Quadro 1), representa a divisão do trabalho sociológico, a partir da qual os sociólogos se especializam em um ou mais tipos de conhecimento atestado, e dentro da qual eles se movem conforme a progressão de suas carreiras. A divisão do trabalho também representa uma configuração da dominação acadêmica, que varia conforme o país e a época.

Embora a sociologia norteamericana seja hoje fortemente direcionada à sociologia profissional, isso nem sempre foi assim. Essa sociologia nasceu no século XIX, como sociologia pública, e desenvolveu um forte impulso público na primeira metade do século XX. Nós também não devemos generalizar acerca da sociologia norteamericana na atualidade, pois as características do campo diferem muito, desde uma faculdade comunitária, que enfatiza totalmente o ensino, para uma universidade pública do sistema estadual, a qual, por sua vez, apresenta aparência muito distinta, com os departamentos de pesquisa de excelência.
Vamos adiante e tomemos dois contextos nacionais opostos. Na Rússia, a sociologia para políticas públicas vem emergindo sem ser amparada por uma sociologia profissional igualmente poderosa, ao passo que, nos países escandinavos, a sociologia para políticas públicas também é influente, sendo, porém, apoiada por (e estando em débito com) um ímpeto público e um ímpeto profissional igualmente poderosos. Na África do Sul, na Índia e no Brasil, o ímpeto público é mais forte, muito embora também haja aí uma crescente pressão para que os sociólogos ingressem no campo das políticas públicas - pressões que vêm do Estado e da administração universitária e são intensificadas, pelo menos na África do Sul, pela desmobilização geral da sociedade civil. Na França, o impulso público é notoriamente forte, acompanhado tanto pela sociologia crítica como pela sociologia profissional. Mas, com frequência, eu tenho ouvido os sociólogos franceses lastimarem a debilidade da sua sociologia profissional - falando contra a sociologia "hipercrítica”, de um lado, e excomungando os “especialistas”, por outro. Nós não podemos esquecer que, em muitos países pobres, a sociologia sequer existe e, por isso, falar de uma divisão do trabalho sociológico aí não faz o menor sentido. Mapear os diferentes campos nacionais da sociologia seria uma imensa tarefa!

Nós podemos identificar também os contornos de uma divisão internacional do trabalho sociológico, na qual os campos nacionais seriam organizados segundo alguma forma de hierarquia reconhecível. Aqui, é possível observar um processo de “internacionalização”, manifesto por crescentes pressões dos Estados para ranquear sua educação superior com base numa escala internacional, classificando suas universidades, departamentos e acadêmicos individuais nesses termos. O critério gira em torno de alguma espécie de "credencial internacional”, com publicações em jornais de alcance mundial e citações feitas por especialistas internacionais, em que por internacional deve-se ler Estados Unidos e Europa.

Esse par, profissionalização e internacionalização, obriga os acadêmicos a analisarem seus 
póprios países através da ótica dum paradigma estrangeiro. Isso os torna mais comprometidos com acadêmicos estrangeiros que com suas próprias audiências nacionais e regionais. Também os encoraja a escrever em "sociologuês" ou inglês, para audiências acadêmicas estrangeiras, em vez de escreverem em linguagem acessível à compreensão dos públicos nacional e regional. Casos extremos dessa internacionalização podem ser encontrados em Israel e Taiwan, o que reflete sua situação geopolítica dependente no cenário mundial. Mas, mesmo ali, nós encontramos reações locais à tendência dominante, bifurcando-se o campo numa ala orientada à comunidade internacional e uma vanguarda pública orgânica orientada para as comunidades locais. O Japão é um caso sobremaneira interessante, embora pouco conhecido, no qual a sociologia cultivou sua própria tradição nacional, ao mesmo tempo em que foi fortemente influenciada do exterior pela ciência social alemã (antes da Segunda Guerra) e pela sociologia norteamericana (após a Segunda Guerra). Mesmo assim, à medida que ela vem se tornando uma liderança mundial, a sociologia japonesa também vem desenvolvendo sua firme independência frente às pressões externas, baseada em suas prestigiosas universidades e tradições acadêmicas.

Essa hegemonia estadunidense e europeia provoca reações que vão desde uma aceitação a vincular-se totalmente às metrópoles setentrionais, até uma rejeição violenta contra tudo o que é ocidental, promovendo-se sociologias provincianas e, portanto, arriscando-se ao isolamento. Adotando o meio-termo, há diálogos regionais emergentes, tais como aquele iniciado pela Sociedade Japonesa de Sociologia com a Coreia e a China; ou as poderosas comunidades de colaboração, erguidas na América Latina, representadas na Associação Latino-americana de Sociologia - ALAS. Sociologias subalternas também podem desafiar a hegemonia do Norte, ao afirmarem o lado crítico e o lado público da sociologia, em resposta ao profissionalimo e à padronização - movimentos que podem ser vistos em países semiperiféricos como a Índia, o Brasil e a África do Sul. Essas tendências jamais negam a importância da profissionalização ou da internacionalização. Em lugar disso, elas tornam esses fenômenos responsáveis pelas questões locais, transformando a profissionalização formal, como diria Weber, numa profissionalização significativa.

A hegemonia da teoria social europeia e dos programas de pesquisa estadunidenses - esses últimos apoiados por enormes recursos materiais - é visível pelo mundo afora. Mas nós devemos tomar cuidado para não cair num essencialismo da sociologia estadunidense, uma vez que ela também possui divisões internas. Em nenhum outro lugar isso é mais evidente que nos "embates da sociologia pública”, travadas numa ampla série de eventos, noticiada e publicada numa série de jornais, como Social Forces, Social Problems, The American Sociologist, Contemporary Sociology e Critical Sociology, bem como numa série de volumes editados.

As linhas do embate, que é de se esperar que sejam várias, mantêm-se ao longo das mesmas linhas de divisão do trabalho sociológico. Assim, os sociólogos profissionais estão mais propensos a condenar a sociologia pública a uma ciência de baixa qualidade, sem credibilidade, e que dividiria a disciplina, ou acobertaria sua politização. Costumase dizer que a sociologia não é uma ciência madura o bastante para ir ao público ou, se é para existir alguma sociologia pública, então, que ela esteja (pelo menos) sob o controle de sociólogos profissionais "responsáveis". Os sociólogos críticos e públicos contra-atacam essa visão, denunciando a irrelevância, o chauvinismo e a miopia da sociologia profissional, vendo as reivindicações profissionais por neutralidade axiológica como uma ideologia que dissimula seu próprio projeto político, desdenhando secretamente da contaminação do cientificismo. As explosões nas batalhas da sociologia pública vêm de um embate pela (re)articulação da divisão do trabalho sociológico.

Ao apontar para a hegemonia da sociologia estadunidense, portanto, podemos falar em duas hegomonias igualmente contestadas. De um lado, há uma hegemonia global externa, que depende da 
absorção e irradiação de indivíduos, recursos, métodos e ideias vindos dos Estados Unidos. Sociologias alternativas, provenientes da Europa e do hemisfério sul (Alatas, 2006; Connell, 2007), precisam desafiar a hegemonia global norteamericana. Por outro lado, essa hegemonia global externa é dependente da hegemonia nacional interna da sociologia profissional estadunidense. Como eu já sugeri, essa hegemonia da sociologia profissional também é contestada - a própria existência das guerras da sociologia pública testemunham tal contestação. Visto que o campo sociológico estadunidense está longe de ser unido, é provável que alianças intersetoriais e transnacionais entre perspectivas subalternas, dentro dos próprios Estados Unidos, como as pesquisas feministas, os estudos raciais críticos, a sociologia da libertação, o marxismo e a pesquisa participante, por um lado, e perspectivas subalternas em outros países, por outro lado, sejam construídas. Com efeito, a maneira mais eficaz de se desvencilhar da hegemonia norteamericana pode vir das alianças que conectam projetos críticos-públicos dentro do ventre da "besta", ou em apoio a projetos transformadores similares, em realização em outros países.

\section{SOCIOLOGIA: a unidade na diversidade}

Durante os últimos cinco anos, debates, discussões e simpósios a respeito da sociologia pública podem ser vistos não apenas nos Estados Unidos, mas também em outros países - países tão distantes entre si como França, Rússia, China, Itália, Dinamarca, Alemanha, Inglaterra, Austrália, Portugal, Hungria, Canadá, Nova Zelândia, África do Sul, Irã, Hong Kong e Brasil. A questão mostrase mais ou menos polêmica onde quer que ela seja levantada ou insinuada. Os cismas e conflitos, entretanto, variam dramaticamente de lugar para lugar, refletindo a própria diferença dos campos que eles dividem. Se há tanta divisão, como eu poderia postular a existência de um projeto coletivo comum?

Em primeiro lugar, embora os conflitos se- jam profundos, eles atuam dentro dum consenso coletivo sobre os principais parâmetros do nosso campo. Os protagonistas se definem, em relação uns aos outros, por meio das categorias de profissional, crítico, público, e para políticas públicas. Com efeito, pode-se dizer que os antagonismos efetivamente constituem e reproduzem os contornos da divisão do trabalho sociológico. É através dos conflitos que o campo sociológico é produzido e definido, não através de um consenso artificial e obrigatório. Essa, aliás, é a marca da vitalidade da sociologia.

Em segundo lugar, eu iria mais além para dizer que uma sociologia florescente requer todos os quatro tipos de conhecimento sociológico, sublinhando que seu antagonismo é uma interdependência fundamental: o alicerce de uma divisão orgânica e simbiótica do trabalho. A sociologia profissional retira sua energia das infusões da sociologia pública, avança sob as pressões da sociologia crítica e é, com frequência, sustentada pela sociologia para políticas públicas. Da mesma forma, a sociologia pública não poderia existir, a menos que a sociologia profissional não conformasse e sustentasse sua autonomia vis-à-vis os públicos aos quais ela se engaja. Ela depende também da sociologia crítica para lhe infundir valores que a ajudem a manter ou corrigir o curso. Por sua vez, a sociologia crítica depende da sua antagonista, a sociologia profissional, sem a qual ela nada teria para criticar! Todos esses antagonismos estão encadeados numa divisão comum do trabalho. Na medida em que a sociologia profissional torna-se irrelevante, a sociologia crítica torna-se dogmática, a sociologia para políticas públicas torna-se servil, e a sociologia pública se transforma em populismo. Quer dizer, na medida em que um dado tipo perde contato e respeito pelos demais, nossa disciplina perde vitalidade.

Essa hipotética unidade na diversidade ou essa interdependência antagonística - é fundamentada num ponto de vista sociologicamente compartilhado, a saber, o ponto de vista da sociedade civil, por meio da qual eu me refiro às organizações, associações e movimentos que não fazem parte 
nem do Estado nem do mercado. Sem a sociedade civil, não apenas a sociologia pública desaparece, mas também a sociologia como um todo some como aconteceu na Alemanha sob Hitler, no Chile sob Pinochet e na China sob Mao Tsé-Tung.

Nada mais previsível e explicável que isso. A sociologia apareceu na Europa e nos Estados Unidos lado a lado com a emergência da sociedade civil, no final do século XIX. Dizer que nós, sociólogos, estudamos o mundo do ponto de vista da sociedade civil não significa que nós estudamos apenas a sociedade civil. Longe disso! Nós também estudamos o mercado, mas do ponto de vista do social: as condições sociais de existência dos mercados, aquilo que Gramsci chamou de "mercado determinado", o modo como a produção se conecta ao movimento operário etc. Nós também estudamos o Estado, mas igualmente sob a perspectiva do seu apoio social (a família, a educação, os partidos políticos etc.) ou suas consequências de interesse sociológico (atomização, repressão, mobilização etc.).

Nesse aspecto, nós nos distinguimos dos economistas - que estudam o mundo do ponto de vista do mercado e sua expansão - e dos cientistas políticos - que estudam o mundo do ponto de vista do Estado e da consolidação e manutenção do seu poder -, embora, em ambos os casos, sempre existam discursos dissidentes, porque, tal como a sociologia, a economia e a ciência política também são campos de poder. Por isso, a importância da sociologia pública se deve não apenas à vitalidade que ela transmite à sociologia profissional, mas também aos diálogos por meio dos quais ela promove a sociedade civil, que é a condição sine qua non de nossa própria disciplina. Assim como o sucesso dos economistas baseia-se em sua capacidade de constituir um objeto de estudo que nós chamamos de economia, e o sucesso dos cientistas políticos jaz em fazer o mesmo com o Estado, o sucesso dos sociólogos está na construção e proteção da sociedade civil - algo sumamente importante na conjuntura atual.

Tem-se dito que a ideia da sociologia pública romantiza a sociedade civil, demonizando, em contrapartida, o Estado e o mercado. Longe disso!
Eu estou muito ciente de como a sociedade civil é clivada por conflitos, dominações e exclusões. Raça, gênero e classe dividem seu terreno. Essas divisões constituem uma das razões pelas quais a sociologia é ela mesma tão clivada e variada, com numerosos subcampos. Analiticamente, nós poderíamos imaginar a sociedade civil como Jano bifronte: de um lado, organizando o consentimento à dominação do Estado e do capital; mas, por outro lado, oferecendo o melhor terreno (embora longe da perfeição idealista) para contermos os ataques do Estado e do capital - ataques que originam e aprofundam várias desigualdades sociais e que vêm se tornando ainda mais agressivos no período recente.

\section{A SOCIOLOGIA E A TERCEIRA ONDA DA MERCANTILIZAÇÃO 5}

Nós estamos entrando, hoje, num período de reação à terceira onda da mercantilização (marketization) - onda que começou em meados dos anos 1970. Nos Estados Unidos, essa terceira onda reverteu muitos dos direitos sociais e civis, assim como algumas políticas públicas distributivas conquistadas desde o New Deal - a começar pela remoção da regulação estatal sobre as economias e a hemorragia do Estado de Bem-estar Social, com base num ataque direto aos sindicatos de trabalhadores e aos direitos civis básicos. No hemisfério sul, isso envolve a reversão dos empreendimentos de desenvolvimento socialistas ou liderados pelo Estado, com sua substituição por projetos de ajuste estrutural baseados em desregulações e privatizações. No antigo mundo comunista, nós presenciamos o esfacelamento dos regimes soviéticos, seguidos por diferentes variedades de "terapias de choque" para provocar (o mais depressa possível) a transição à economia de mercado. Se, na China, o regime comunista não desmoronou, ele decerto injetou na economia doses cavalares ${ }^{5}$ Ver Burawoy, Michael. A sociologia da terceira onda e o
fim da ciência pura. Estudos de sociologia, n. $24,2008$. (N. do T.). 
de mercantilização e de capitalização. A supressão do crescimento econômico conduzido pelos Estados asiáticos sofreu o maior golpe com o agravamento da crise econômica que varreu a região entre 1997 e 1998. Esse ataque indiscriminado ao social é o que lançou a própria sociologia num retraimento defensivo, com algumas notáveis exceções, após sua vibrante expansão durante os anos 1960 e 1970.

Assim como suas predecessoras, essa terceira onda da mercantilização - a primeira teve lugar no século XIX, e a segunda começou após a Primeira Guerra Mundial - vem exibindo as sementes da sua própria exaustão, ao gerar crises de proporções cada vez mais graves. Basta que observemos a desregulação do sistema bancário estadunidense, que vem se devorando rapidamente: um castelode-cartas que veio abaixo com o estouro da bolha hipotecária subprime. Apesar da ajuda financeira sem precedentes, os economistas preveem que esse é o começo de um período de deflação, com uma redução da produção, o que conduzirá ao encolhimento das economias ao redor do globo. O crédito está certamente mais apertado; o desemprego vem atingindo proporções históricas e, na falta de outra vultosa ajuda financeira, a indústria automobilística americana enfrenterá sua crise final. Os prognósticos são pessimistas.
Retornemos à história para vermos o que poderá ocorrer. Tão catastróficas foram as consequências da segunda onda da mercantilização, iniciada com o término da Primeira Guerra Mundial - destruição disseminada, desemprego, fascismo e stalinismo, sem falar na Segunda Guerra Mundial -, que Karl Polanyi, redigindo em 1944 seu canônico trabalho A grande transformação, considerou que todas as lições haviam sido aprendidas pela humanidade e que jamais haveria outra onda de fundamentalismo de mercado. Ele estava errado, mas sua teoria sobre as mercadorias fictícias pode ainda ser usada para enfocar a crise que enfrentamos atualmente. Conforme Polanyi, a existência humana depende de três elementos básicos - terra, trabalho, dinheiro - que, quando submetidos à mercantilização desenfreada, ameaçam a exis- tência da humanidade. Ao se mercadorizar a terra (e nós podemos estender o exemplo para a água e o ar), nós ameaçamos a própria reprodução humana; ao se mercadorizar o trabalho, nós ameaçamos sua capacidade produtiva; ao se transformar o dinheiro em mercadoria, nós inviabilizamos os empreendimentos econômicos. A sociedade, quando confrontada com a mercantilização desses três elementos, segundo Polanyi (1944), ou reage ou se destrói. Mas suas reações não são sempre positivas e benéficas, como no caso dos regimes autoritários e repressores que (não raro) governam seu povo com pulso de ferro.

Os sociólogos precisam abandonar seus nichos, dentro dos quais se abrigaram enquanto a euforia do mercado rugia ao seu redor. Eles precisam lutar por um contra-ataque centrado na sociedade civil, e não por uma reação que instale um governo despótico ou apele para uma reforma utópica do mercado. Não faltam exemplos que nos inspirem nisso. Os sociólogos já estiveram profundamente comprometidos com as lutas antiprivatização - como na Índia, em torno das Zonas Econômicas Especiais; como na África do Sul, acerca da privatização dos recursos hídricos ou da destruição dos loteamentos clandestinos; como no Brasil, sobre a desapropriação dos latifúndios improdutivos, e por aí vai. Hasegawa (2004) tem escrito sobre as intervenções dos cidadãos japoneses em diversos movimentos ambientalistas, contra a energia nuclear, a construção de represas e o reflorestamento. Os sociólogos podem colaborar frente a frente com ativistas como sociólogos públicos orgânicos -, ou levantar questões ambientais na esfera pública - como sociólogos públicos tradicionais. Deve haver espaço para ambos!

De maneira similar, a terceira onda da mercantilização tem desferido derrotas devastadoras à organização dos trabalhadores pelo mundo afora. Mas nós também observamos exemplos animadores de sociólogos que dão vazão a novas ideias acerca do movimento sindical na África do Sul, nos Estados Unidos, no Brasil e em outros países. Na Espanha, os sociólogos estão empenhados na 
Cooperativa Mondragón, como um outro modo de proteger o trabalho da desregulação econômica. Por fim, nós poderíamos considerar o atual desmanche financeiro como um caso específico da desenfreada transformação do dinheiro em mercadoria, que leva os Estados ao redor do globo a socorrerem os mesmíssimos bancos cuja insana busca por lucro provocou o colapso atual. Essa não é a especialidade da sociologia pública, embora hoje deva sê-lo, na medida em que os vários termos da ajuda financeira trarão diferentes implicações para a sociedade. Nesse campo como em outros, a América Latina, novamente, tem provado ser a terra natal de exemplos brilhantes, como no caso do orçamento participativo, que põe as finanças municipais sob o controle da população - prática que vem inspirando sociólogos públicos orgânicos em outros países.

Em suma: nós, hoje, atravessamos a encruzilhada da história, onde o velho fundamentalismo do mercado agoniza e novos contra-ataques já ganham terreno. Nós estamos navegando em águas turbulentas, onde somente os sociólogos, munidos dum entendimento sobre o Estado e sobre o mercado do ponto de vista da sociedade civil, poderão nos auxiliar numa guinada em direção a águas mais calmas. Parafraseando Marx, nossa disciplina poderá partir de um campo-em-si, definido por sua divisão antagônica e fragmentária do trabalho, rumo a um campo-para-si, com sua divisão sinérgica e simbiótica do trabalho, transformada num movimento social pela expansão da esfera pública, enraizada numa sociedade civil poderosa e autogerida. Ou então nossa disciplina poderá se refugiar em intrigas palacianas inúteis, tocando violino enquanto assistimos Roma em chamas.

(Recebido para publicação em abril de 2009) (Aceito em julho de 2009)

\section{REFERÊNCIAS}

ALATAS, S. F. Alternative discourses in asian social science. New Delhi: Sage Publications, 2006.

BELLAH, R; MADSEN, R.; SULLIVAN, W. M.; SWIDLER, A.; TIPTON, T. Habits of the heart: individualism and commitment in american life. Berkeley: University of California Press, 1985.

BLAUNER, R. Racial oppression in America. New York: Harper Row, 1972.

BOURDIEU, P. On television. New York: New Press, 1998.

Pascalian meditations. Stanford: Stanford University Press, 2000

BOYER, E. L. Scholarship reconsidered: priorities of the professoriate. New York: The Carnegie Foundation for the Advancement of Teaching, 1990.

CONNELL, R. Southern theory. Australia: Allen and Unwin, 2007.

FREIRE, P. Pedagogy of the oppressed. New York: Continuum, 1970.

GIDDENS, A. The constitution of society. Berkeley: University of California Press, 1984.

GOULDNER, A. The coming crisis of western sociology. New York: Basic Books, 1970.

GRAMSCI, A. Selections from the Prison Notebooks. New York: International Publishers, 1971.

HASEGAWA, K. Constructing civil society in Japan. Melbourne: Trans Pacific Press, 2004.

HOCHSCHILD, A.; MACHUNG, A. The second shift: working parents and the revolution at home. New York: Viking, 1989.

Time bind: when work becomes home and home becomes work. New York: Metropolitan Books, 1997.

LAKATOS, I. The methodology of scientific research programmes. Cambridge: Cambridge University Press, 1978.

LYND, R. Knowledge for what? the place of social sciences in American culture. Princeton: Princeton University Press, 1939.

Mills, C. W. The power elite. New York: Oxford University Press, 1956.

The sociological imagination. New York: Oxford University Press, 1959.

POLANYI, K. The great transformation. Boston: Beacon Press, 1944.

SMITH, D. The everyday world as problematic. Boston: Northeastern University Press, 1987.

Institutional ethnography: a sociology for the people. Lanham: Roman and Littlefield, 2005.

SOROKIN, P. Fads and foibles in modern sociology and related sciences. Chicago: Henry Regnery, 1956.

TOURAINE, A. Return of the actor. Minneapolis: University of Minnesota, 1988. 


\section{PUBLIC SOCIOLOGY IN THE AGE OF BARACK OBAMA}

\section{Michael Burawoy}

This article was the basis of an address to the Japanese Sociological Society, Tohoku University. We revisit the main points of the public sociology. It is made taking into account the capitalist system international crisis. I do believe as sociologists, despite national traditions and global inequalities, we do share a common interest, and even mission, to combat the market fundamentalism that has spread throughout the world - a project that is now showing signs of fissure and exhaustion. Despite the measures against crisis put forward by governments sociologists have their own interest in channeling the counter-movements toward a stronger and more democratic civil society and a more robust and inclusive public sphere.

KEYwORDS: public sociology, civil society, public sphere, market fundamentalism.

\section{LA SOCIOLOGIE PUBLIQUE AU TEMPS DE BARACK OBAMA}

\section{Michael Burawoy}

Partant d'un discours adressé à la Société Japonaise de Sociologie, au sein de l'Université de Tohoku, ce travail reprend les formulations centrales de la sociologie publique en identifiant les quatre styles du faire sociologique, à la lumière du scénario présenté par la crise profonde par laquelle passe le système capitaliste mondial. Bien que connaissant les différentes traditions nationales ainsi que l'inégalité internationale, et malgré cellesci, nous sommes convaincus qu'en tant que sociologues nous partageons une ambition et une mission commune, c'est-à-dire le combat contre le paradigme basé sur le fondamentalisme du marché qui accuse actuellement de graves signes de crise et d'épuisement. C'est dans ce sens qu'il incombe aux sociologues de réaliser une tâche primordiale, celle de canaliser les réactions face à la crise pour en arriver à la création d'une société civile plus forte et plus démocratique ainsi que d'une sphère publique plus robuste et inclusive.

MoTS-CLÉs: sociologie publique, société civile, sphère publique, fondamentalisme de marché.

Michael Burawoy - Doutor em Sociologia pela Universidade de Chicago. Professor do Departamento de Sociologia da Universidade da Califórnia em Berkeley e Vice-Presidente da Associação Sociológica Internacional - ISA. Desenvolve pesquisas nas áreas de Sociologia do Trabalho e Teoria Sociológica. Sua mais recente publicação é o livro intitulado The extended case method. 